\title{
Intracellular type III secretion by cytoplasmic Shigella flexneri promotes caspase-1-dependent macrophage cell death
}

\author{
Gunnar N. Schroeder, Naja J. Jannt and Hubert Hilbi \\ Institute of Microbiology, Swiss Federal Institute of Technology (ETH) Zürich, \\ Wolfgang-Pauli-Strasse 10, 8093 Zürich, Switzerland
}

Correspondence

Hubert Hilbi

hilbi@micro.biol.ethz.ch

Received 22 February 2007

Revised 11 May 2007

Accepted 1 June 2007

\section{INTRODUCTION}

Many symbiotic or pathogenic Gram-negative bacteria employ a type III secretion system (T3SS) to establish a replicative niche (Cornelis, 2006; Galan \& Wolf-Watz, 2006). The complex T3SSs are evolutionarily related to flagellar secretion systems and composed of a basal structure spanning the two bacterial membranes, a hollow needle (or pilus/filament) and a hydrophobic translocator complex inserted into eukaryotic target membranes. Some T3SSs deliver more than 20 different 'effector' proteins into target cells, where they subvert cellular functions in favour of the bacteria. In the eukaryotic host cells, the bacterial effectors target phosphoinositide metabolism, GTP cycles,

tPresent address: University Hospital Basel, Department of Research (Infectious Diseases), Hebelstrasse 20, 4031 Basel, Switzerland.

Abbreviations: CCCP, carbonyl cyanide $m$-chlorophenylhydrazone; FLICA, carboxyfluorescein-YVAD-fmk; LAMP-1, lysosome-associated membrane protein 1; LDH, lactate dehydrogenase; TPPII, tripeptidyl peptidase II; T3SS, type III secretion system; TRITC, tetramethylrhodamine isothiocyanate.

A supplementary figure showing the reversible inhibition by CCCP of $S$. flexneri growth is available with the online version of this paper. phosphoprotein signalling, cytoskeletal and vesicle dynamics, or apoptotic pathways (Cossart \& Sansonetti, 2004; Hilbi, 2006; Rosenberger \& Finlay, 2003; Schlumberger \& Hardt, 2006).

Shigella flexneri, the causative agent of a severe diarrhoea termed bacillary dysentery (shigellosis), employs a T3SS to invade non-phagocytic epithelial cells and to kill macrophages (Cossart \& Sansonetti, 2004). The S. flexneri T3SS is encoded by the $m x i$ and spa genes on the $214 \mathrm{~kb}$ virulence plasmid (Buchrieser et al., 2000). Investigations by electron microscopy revealed that the Mxi-Spa needle complex is a canonical T3SS composed of a basal body and a needle, the major subunit of which (MxiH) is required for the secretion of effector proteins (Blocker et al., 2001; Tamano et al., 2000). Secretion by the Mxi-Spa apparatus is triggered upon contact with host cells (Ménard et al., 1994a; Watarai et al., 1995) in a process that requires hostcell-membrane cholesterol (Hayward et al., 2005; Lafont et al., 2002; van der Goot et al., 2004). In vitro, the secretion of Mxi-Spa effectors is triggered by the dye Congo red (Bahrani et al., 1997), as well as by lipid 'rafts' (detergent-resistant membrane domains enriched in sphingolipids and cholesterol) or by raft-like liposomes (van der 
Goot et al., 2004). Interestingly, a component of the MxiSpa translocon, IpaB, associates with raft-like liposomes (van der Goot et al., 2004) and directly binds cholesterol with high affinity (Hayward et al., 2005). This property of IpaB likely accounts for the cholesterol-dependent secretion through the Mxi-Spa T3SS, as well as for the cholesteroldependent membrane insertion of the translocon.

The Ipa (invasion plasmid antigen) proteins (IpaA-D) are well-characterized Mxi-Spa substrates that promote the entry of S. flexneri into non-phagocytic cells (Cossart \& Sansonetti, 2004). IpaB together with IpaD controls secretion through the Mxi-Spa T3SS (Ménard et al., 1994a). IpaB and IpaC separately bind to the chaperone IpgC in the bacterial cytoplasm and associate upon secretion (Ménard et al., 1994b), thereby forming the pore of the translocon, which is inserted into eukaryotic membranes (Blocker et al., 1999). Purified IpaB and IpaC integrate into host-cell plasma membranes (De Geyter et al., 1997, 2000), and IpaB induces liposome fusions in vitro (Hume et al., 2003). IpaD localizes to the tip of the needle prior to secretion and likely serves as a scaffold for the assembly of the hydrophobic IpaBC translocon (Espina et al., 2006). IpaB and IpaC also have effector functions: while microinjected IpaC triggers actin polymerization and filopodia formation in epithelial cells (Tran Van Nhieu et al., 1999), microinjected IpaB triggers cell death in macrophages (Chen et al., 1996). Moreover, upon contact with epithelial cells IpaB binds to the hyaluron receptor CD44 (Skoudy et al., 2000). The resulting IpaB-CD44 complex is associated with lipid rafts, which play a functional role during the entry of $S$. flexneri into host cells (Lafont et al., 2002).

Upon interaction with macrophages, $S$. flexneri promotes its own uptake by means of the Mxi-Spa T3SS and IpaC (Kuwae et al., 2001). The insertion of IpaC into host-cell membranes signals a distinct entry pathway characterized by a specific protein phosphorylation pattern. Subsequently, S. flexneri escapes the phagosome and, dependent on IpaB, triggers a pro-inflammatory type of apoptosis in macrophages (Zychlinsky et al., 1994b). IpaB is sufficient to induce apoptosis, co-localizes with caspase-1 [interleukin (IL)-1 $\beta$ converting enzyme] in the macrophage cytoplasm and directly binds caspase-1, but not caspase- 2 or -3 (Chen et al., 1996; Guichon et al., 2001; Hilbi et al., 1998; Thirumalai et al., 1997). The apoptotic pathway is characterized by the requirement and proteolytic activation of caspase- 1 but not other family members such as caspase3 or caspase-11 (Chen et al., 1996; Hilbi et al., 1997, 1998). Moreover, pharmacological evidence indicates that the cytoplasmic, high-molecular-mass serine protease tripeptidyl peptidase II (TPPII) participates upstream of caspase-1 in this cell-death pathway (Hilbi et al., 2000). The activation of caspase-1 and induction of macrophage apoptosis was found to be inhibited by cholesterol depletion after phagocytosis and phagosomal escape of $S$. flexneri, suggesting that membrane association of IpaB contributes to the activation of caspase-1 (Schroeder \&
Hilbi, 2006). Activation of caspase-1 leads to the proteolytic maturation and secretion of IL- $1 \beta$ and IL-18 (Hilbi et al., 1997; Islam et al., 1997; Sansonetti et al., 2000; Zychlinsky et al., 1996), thus initiating the massive inflammation characteristic of shigellosis. While this cell death pathway is clearly dependent on caspase-1, it shows features of both apoptosis and necrosis (Haimovich \& Venkatesan, 2006). Finally, S. flexneri can also induce a caspase-1- and IpaB-independent cell-death pathway, which is triggered by bacterial LPS (lipid A) delivered to the macrophage cytoplasm (Suzuki et al., 2005).

Here, we provide evidence that in S. flexneri-infected macrophages the translocator/effector protein IpaB is intracellularly secreted over a prolonged time, during which the bacterial pool is gradually depleted. Furthermore, using the protonophore carbonyl cyanide $m$ chlorophenyl-hydrazone (CCCP), which has been shown to block Yersinia type III secretion (Wilharm et al., 2004), we inhibited Shigella type III secretion after the escape of the bacteria from the phagosome and demonstrated that intracellular type III secretion promotes macrophage cell death.

\section{METHODS}

Cell culture, bacteria and plasmids. Mouse J774 macrophages and peritoneal macrophages from $\mathrm{B} 57 \mathrm{BL} / 6$ mice were cultured in a humidified atmosphere of $5 \% \mathrm{CO}_{2}$ at $37{ }^{\circ} \mathrm{C}$ in RPMI 1640 glutamine medium, supplemented with $10 \%$ fetal calf serum (OmniLab), $2 \mathrm{mM}$ L-glutamine and penicillin/streptomycin $\left(50 \mu \mathrm{g} \mathrm{ml}^{-1}\right.$ each). The following $S$. flexneri serogroup 5a strains were grown aerobically in tryptone soy broth (TSB) medium (Oxoid): M90T (clinical isolate; Sansonetti et al., 1982), BS176 (virulence-plasmid-cured derivative of M90T), SF401 (type III secretion negative $\Delta m x i D$ mutant; Allaoui et al., 1993), and SF620 (non-polar ipaB deletion mutant; Ménard et al., 1993). Where indicated, the corresponding strains containing the plasmid pM979 (Stecher et al., 2004) constitutively expressing green fluorescent protein (GFP) or the arabinose-inducible IpaB expression plasmid pGNS025 were grown in presence of ampicillin (Applichem; $100 \mu \mathrm{g} \mathrm{ml}^{-1}$ ). IpaB was induced with $0.1 \%$ arabinose [stock $20 \%(\mathrm{w} / \mathrm{v})$ ] in Dulbecco's phosphate-buffered saline without calcium and magnesium (D-PBS; Invitrogen) added to the bacterial subcultures. To test the effect of CCCP (Sigma) on the growth of $S$. flexneri, the protonophore $(25 \mu \mathrm{M})$ was added $2 \mathrm{~h}$ after inoculation, and $2.5 \mathrm{~h}$ later the bacteria were centrifuged and resuspended in TSB medium with or without $25 \mu \mathrm{M}$ CCCP.

To construct plasmid pGNS025, expressing IpaB under the control of an arabinose-inducible promoter, the open reading frame of $i p a B$ was amplified by PCR (primers: 5'-CGCGGCTAGCAGGAGGAATTCACCATGCATAATGTAAGCACCACAAC- $3^{\prime}$ and $5^{\prime}$-GGGGCTGCAGTCCTTATTTGTATCAAGCAGTAGT-3') using as a template the vector p179 (Maurelli et al., 1985), cut with NheI/PstI, and cloned into the same restriction sites of pBAD24 (Guzman et al., 1995). To verify the construct, the insert of the plasmid was sequenced.

Infection of macrophages. J774 macrophages were infected with exponentially growing $S$. flexneri essentially as described by Schroeder \& Hilbi (2006). To study the effects of ionophores or inhibitors, the compounds were added to macrophages from stock solutions: YVADcmk (50 mM in DMSO; Bachem), AAF-cmk (50 mM in DMSO; Bachem), oligomycin (125 mM in EtOH), staurosporine (1 mM in 
DMSO) or $25 \mathrm{mM}$ each of CCCP (DMSO), gramicidin (ethanol), monensin (methanol) or nigericin (chloroform).

Cytotoxicity assays. Cytotoxicity triggered by S. flexneri (m.o.i. 50, 2$3 \mathrm{~h})$ or staurosporine $(1 \mu \mathrm{M}, 9 \mathrm{~h})$ was quantified by a lactate dehydrogenase (LDH) release assay using the CytoTox96 kit (Promega) as described previously (Hilbi et al., 1998, 2000; Zychlinsky et al., 1994a). The formula [(experimental release-spontaneous release)/(total release - spontaneous release)] $\times 100$ was used. Spontaneous and total release was determined using the proper solvent and reagent controls where necessary. Notably, the values were corrected for weak cytotoxic effects of CCCP $(<10 \% \mathrm{LDH}$ release). In experiments using $S$. flexneri harbouring pGNS025, the assay was performed in D-PBS instead of serum-free RMPI 1640 medium.

Immunofluorescence microscopy. Immunofluorescence staining of LAMP-1 (lysosome-associated membrane protein 1) and IpaB in $S$. flexneri-infected J774 macrophages was performed as described previously (Schroeder \& Hilbi, 2006) and analysed with an Axiovert 200M inverted laser confocal microscope (Zeiss) equipped with a $100 \times$ objective (Zeiss, Plan-Neofluar, aperture 1.3, oil). Briefly, macrophages $\left(2-3 \times 10^{5}\right.$ per coverslip in a 24 -well plate $)$ were infected with S. flexneri constitutively expressing GFP (m.o.i. 20). Where indicated, $25 \mu \mathrm{M}$ or $100 \mu \mathrm{M}$ CCCP was added at different time points. At the time points indicated, the cells were washed three times with PBS, fixed with $4 \%$ paraformaldehyde in PBS (30 min), permeabilized with chilled methanol (5 min) and blocked with PBS containing $5 \%$ $(\mathrm{w} / \mathrm{v})$ sucrose and $2 \%(\mathrm{v} / \mathrm{v})$ normal human serum $(30 \mathrm{~min})$. Samples were incubated for $1 \mathrm{~h}$ with either a monoclonal mouse anti-IpaB primary antibody (clone H16, 1:300; Barzu et al., 1993) or a monoclonal rat anti-LAMP-1 antibody (clone 1D4B, 1:50; Developmental Studies Hybridoma Bank, University of Iowa), followed by Cy3-conjugated goat anti-mouse $(1: 200$; Jackson Immuno Research Laboratories) or TRITC-labelled rabbit anti-rat $\operatorname{IgG}(1: 200$; Sigma $)$ secondary antibodies $(1 \mathrm{~h})$. Bacterial invasion and co-localization with LAMP-1 was quantified by evaluating 100 randomly selected macrophages. Intracellular IpaB was stained after permeabilization of the bacteria with lysozyme as described by Schlumberger et al. (2005).

Quantification and subcellular localization of IpaB in infected macrophages. To determine the effect of CCCP on the intracellular amount and the subcellular localization of IpaB, we used a fractionation protocol described previously (Schroeder \& Hilbi, 2006). Briefly, J774 macrophages $\left(1.2-1.4 \times 10^{6}\right.$ per well, 6 wells per sample) were seeded overnight, washed and infected with $S$. flexneri (m.o.i. 100). Where indicated, $25 \mu \mathrm{M}$ CCCP was added 15 min postinfection and maintained at this concentration throughout the fractionation. At $45 \mathrm{~min}$ post-infection, the infected macrophages were washed, scraped, centrifuged, suspended in $\mathrm{H}_{2} \mathrm{O}$ supplemented with $0.1 \mathrm{mg}$ gentamicin $\mathrm{ml}^{-1}$ and $1 \mathrm{mM}$ PMSF and mechanically lysed in a Dounce homogenizer. To control for the efficiency of scraping and lysis, the protein concentration was determined by a Bradford assay in the samples and adjusted to the same amount prior to gel electrophoresis. The lysates were cleared, and the pellets thus obtained (nuclei and intracellular bacteria) were resuspended in $200 \mu \mathrm{l}$ SDS loading buffer. The post-nuclear supernatant was centrifuged again to remove remaining bacteria, and subsequently fractionated into membranes and cytosol by ultracentrifugation. IpaB and the endoplasmic reticulum membrane marker calnexin were visualized by immuno-blotting using the anti-IpaB H16 antibody or a goat anti-calnexin antibody (c-20; Santa Cruz Biotechnologies) and peroxidase-labelled secondary antibodies (goat anti-mouse IgG, Sigma; rabbit anti-goat IgG, Santa Cruz Biotechnology) as described by Schroeder \& Hilbi (2006).

Induction of type III secretion by Congo red. Congo red-induced secretion of IpaB was assayed as described previously (Bahrani et al.,
1997; Schroeder \& Hilbi, 2006). Briefly, bacterial subcultures were grown to an $\mathrm{OD}_{600}$ of approximately 1 , corresponding to $6 \times 10^{8}$ c.f.u. $\mathrm{ml}^{-1}$. In experiments where IpaB was expressed from the plasmid pGNS025, subcultures were supplemented with $0.1 \%$ arabinose. Then $0.5 \mathrm{ml}$ of this culture was centrifuged $(5 \mathrm{~min}$, $16000 \mathrm{~g}$ ) and washed with PBS. The bacteria were resuspended in $500 \mu \mathrm{l}$ PBS with or without $20 \mu \mathrm{M}$ Congo red in the presence of different concentrations of CCCP, incubated for $30 \mathrm{~min}$ at $37{ }^{\circ} \mathrm{C}$ and harvested $\left(20 \mathrm{~min}, 11000 \mathrm{~g}\right.$ at $\left.20^{\circ} \mathrm{C}\right)$. The decanted supernatant was centrifuged ( $15 \mathrm{~min}, 11000 \mathrm{~g}, 20^{\circ} \mathrm{C}$ ) to remove remaining bacteria. Supernatants and bacterial pellets were boiled in SDS loading buffer and analysed by Western blotting using the H16 mouse anti-IpaB antibody as described above.

Caspase-1 activation assays. The activation of caspase-1 in $S$. flexneri-infected macrophages was assayed by flow cytometry using carboxyfluorescein-YVAD-cmk (FLICA; Immunochemistry Technologies) essentially as described by Schroeder \& Hilbi (2006). Briefly, J774 macrophages $\left(3 \times 10^{5}\right.$ in 24 -well plates) were washed with serumfree RPMI and infected with S. flexneri (m.o.i. 50). Where indicated, the macrophages where treated with CCCP $(25$ or $100 \mu \mathrm{M}, 15$ min postinfection), YVAD-cmk $(100 \mu \mathrm{M})$ or AAF-cmk $(50 \mu \mathrm{M})$. At $40 \mathrm{~min}$ post-infection, the cell culture supernatant was replaced by $300 \mu \mathrm{l}$ serum-free RPMI containing $0.1 \mathrm{mg} \mathrm{ml}^{-1}$ gentamicin and caspase- 1 FLICA staining reagent (final dilution $0.5 \times$ ). After 60 min incubation at $37^{\circ} \mathrm{C}$, FLICA wash buffer was added. The cells were scraped carefully, washed and fixed according to the manufacturer's instruction. The samples and data were analysed using a LSRII Flow cytometer (BD Biosciences) and 'FlowJo' software (Tree Star), respectively.

To investigate the effect of CCCP on ATP-induced caspase- 1 activation, $3 \times 10^{5}$ J774 macrophages were seeded in 24-well plates, treated overnight with $1 \mu \mathrm{g} \mathrm{LPS} \mathrm{ml}^{-1}$ (E. coli O111: B4), washed with serumfree RPMI and incubated at $37^{\circ} \mathrm{C}$ with $1 \mathrm{mM}$ ATP (stock $100 \mathrm{mM}$; Fermentas) in the absence or presence of $100 \mu \mathrm{M}$ CCCP added $30 \mathrm{~min}$ after the ATP. Simultaneously with CCCP, the caspase-1 FLICA staining reagent was added to each sample. After 90 min incubation the samples were analysed by flow cytometry as described above.

Maturation of IL-1 $\beta$ in S. flexneri-infected peritoneal macrophages. Macrophages from C57BL/ 6 mice were harvested 3 days after peritoneal injection of $1 \mathrm{ml}$ aged BBL thioglycollate medium Brewer modified (Becton Dickinson), $4 \%$ in PBS, and seeded at $1.2-$ $1.5 \times 10^{6}$ cells per well (24-well plate). The macrophages were treated with $1 \mu \mathrm{g} \mathrm{LPS} \mathrm{ml} \mathrm{m}^{-1}$ (E. coli O111:B4) overnight to induce pro-IL-1 $\beta$ and with $25 \mu \mathrm{M}$ CCCP at the time points indicated. Immediately prior to the infection, the medium was replaced by $200 \mu \mathrm{l}$ serum-free RPMI, and S. flexneri (m.o.i. 10) was added in $50 \mu \mathrm{l} \mathrm{serum-free}$ RPMI. At 30 min post-infection, $2 \mu \mathrm{l}$ gentamicin was added to a final concentration of $0.1 \mathrm{mg} \mathrm{ml}^{-1}$. At the time points indicated, the infected macrophages were lysed by adding $28 \mu \mathrm{l}$ PBS containing $10 \%$ Triton $\mathrm{X}-100$, and lysates were immediately frozen in liquid nitrogen. Maturation of IL- $1 \beta$ was monitored by Western blotting using a goat anti-mouse IL- $1 \beta$ antibody (R\&D Systems), peroxidaselabelled rabbit anti-goat IgG secondary antibody (Santa Cruz Biotechnology) and the ECL Western Blot Detection kit (Amersham Biosciences) as described previously (Hilbi et al., 1997).

\section{RESULTS}

\section{Intracellular type III secretion of S. flexneri in infected macrophages}

Type III secretion of the effector protein IpaB by $S$. flexneri in infected macrophages was analysed by immunofluorescence 
microscopy using mouse J774 macrophages as host cells and GFP-expressing bacteria. IpaB secreted by S. flexneri wildtype strain M90T was visible as early as $10 \mathrm{~min}$ post-infection (Fig. 1A). Interestingly, IpaB was not distributed homogeneously on the bacterial surface, but accumulated in aggregates on intracellular bacteria. These aggregates were not observed on extracellular bacteria (data not shown). The intensity of IpaB staining on the bacterial surface as well as in the macrophage cytoplasm increased over the entire course of the experiment (75 min), suggesting that within macrophages IpaB was secreted for a prolonged time. As expected, the Mxi-Spa T3SS-deficient strain $\Delta m x i D$ was completely defective for secretion of IpaB. In parallel experiments, the depletion of IpaB from S. flexneri was analysed after permeabilization of fixed bacteria with lysozyme (Fig. 1B). While the amount of IpaB in the bacteria decreased over time, IpaB was still detected in most bacteria after 45$75 \mathrm{~min}$, indicating that the bacteria were not completely depleted of IpaB. Up to 20 min post-infection, IpaB was detected in all bacteria, and at later time points, an increasing number of bacteria apparently lacking IpaB were observed. The kinetics of IpaB secretion and depletion were similar, regardless of whether or not the bacteria were treated with chloramphenicol to block de novo protein biosynthesis prior to an infection (data not shown). In S. flexneri $\Delta m x i D$, used as a T3SS-negative control, the amount of IpaB remained constant. Also, the population of S. flexneri used to infect macrophages appeared to be rather homogeneous, as more than $85 \%$ of exponentially growing $S$. flexneri expressed IpaB prior to an infection (Fig. 1C).

\section{The protonophore CCCP abolishes type III secretion of $S$. flexneri triggered by Congo red or in infected macrophages}

The protonophore CCCP instantly blocks type III secretion of Yersinia enterocolitica Yop proteins and bacterial growth, without affecting the cellular ATP level for at least $1 \mathrm{~h}$ (Wilharm et al., 2004). These findings establish the proton motive force in addition to ATP as an energy source for type III secretion. CCCP likely also inhibits type III secretion of $S$. flexneri, and therefore this membranepermeable compound should be suitable to rapidly block type III secretion by the Mxi-Spa T3SS in vitro and in S. flexneri-infected macrophages at different time points post-infection.

To analyse the effects of CCCP on type III secretion of $S$. flexneri in vitro, secretion was triggered by addition of the dye Congo red (Parsot et al., 1995), in the absence or presence of different concentrations of CCCP. As determined by Western blotting, CCCP dose-dependently inhibited the T3SS-dependent secretion of IpaB into supernatants of $S$. flexneri triggered by Congo red (Fig. 2A). As expected, no IpaB was detected in the virulence-plasmidcured strain BS176. A potential toxic effect of CCCP for S. flexneri was assessed by treating the bacteria with the protonophore during growth in broth. Upon addition of
$25 \mu \mathrm{M}$ CCCP, growth of S. flexneri in broth was immediately abolished, but it resumed upon removal of the compound after $2.5 \mathrm{~h}$ at the initial rate (see Supplementary Fig. S1, available with the online version of this paper). Therefore, under the conditions used, CCCP does not kill S. flexneri.

The effect of CCCP on type III secretion of S. flexneri within infected macrophages was determined by analysing the secretion of IpaB by immunofluorescence and Western blotting. CCCP abolishes phagocytosis (see below), and therefore the protonophore was added 15 min postinfection to J774 macrophages infected with wild-type $S$. flexneri. Upon treatment of $S$. flexneri-infected macrophages with 25 or $100 \mu \mathrm{M} \mathrm{CCCP,} \mathrm{the} \mathrm{number} \mathrm{of} \mathrm{bacteria} \mathrm{showing}$ aggregates of IpaB on the surface, as well as the amount of IpaB translocated into macrophages, decreased in a dosedependent manner, indicating that secretion and translocation of IpaB is impaired (Fig. 2B). While at $25 \mu \mathrm{M}$ CCCP fewer aggregates of secreted IpaB appeared on the bacterial surfaces, at a concentration of $100 \mu \mathrm{M}$, the protonophore almost completely prevented the appearance of the IpaB aggregates, indicating that type III secretion was abolished. No IpaB was released from $m x i D$ mutant $S$. flexneri lacking a functional T3SS (data not shown; compare Fig. 1A).

In an independent approach, the amount of $\mathrm{IpaB}$ in subcellular fractions of S. flexneri-infected macrophages was analysed by Western blotting, after lysates of infected macrophages were separated by low- and high-speed centrifugation steps as detailed in 'Methods' and described elsewhere (Schroeder \& Hilbi, 2006). Quantification by densitometry revealed that upon addition of $25 \mu \mathrm{M}$ CCCP 15 min post-infection, the amount of IpaB in the macrophage cytoplasm and membranes was reduced by $70 \%$ and $30 \%$, respectively, while the amount of the membrane marker calnexin was reduced by approximately $20 \%$ in the experiment shown (Fig. 2C). Thus, CCCP added postinfection significantly reduced the amount of IpaB translocated into the macrophage cytoplasm, demonstrating that under these conditions the protonophore impairs bacterial type III secretion and translocation of IpaB. Translocation of IpaB into macrophages was strictly dependent on a functional T3SS, as upon infection with a $S$. flexneri $\Delta m x i D$ mutant strain, no IpaB was detected in the macrophage cytoplasm or membrane fraction. Furthermore, the amount of IpaB in the fraction intracellular bacteria' was comparable in macrophages infected with wild-type S. flexneri in the presence and absence of CCCP, indicating that CCCP added post-infection did not block the uptake of bacteria (see also below). Taken together, three independent assays revealed that CCCP inhibits Congo-redtriggered type III secretion in vitro and blocks type III secretion in S. flexneri-infected macrophages, respectively.

\section{S. flexneri-triggered macrophage cell death is specifically and reversibly blocked by CCCP}

Since CCCP blocks type III secretion in S. flexneri-infected macrophages, this protonophore can be used to analyse the 


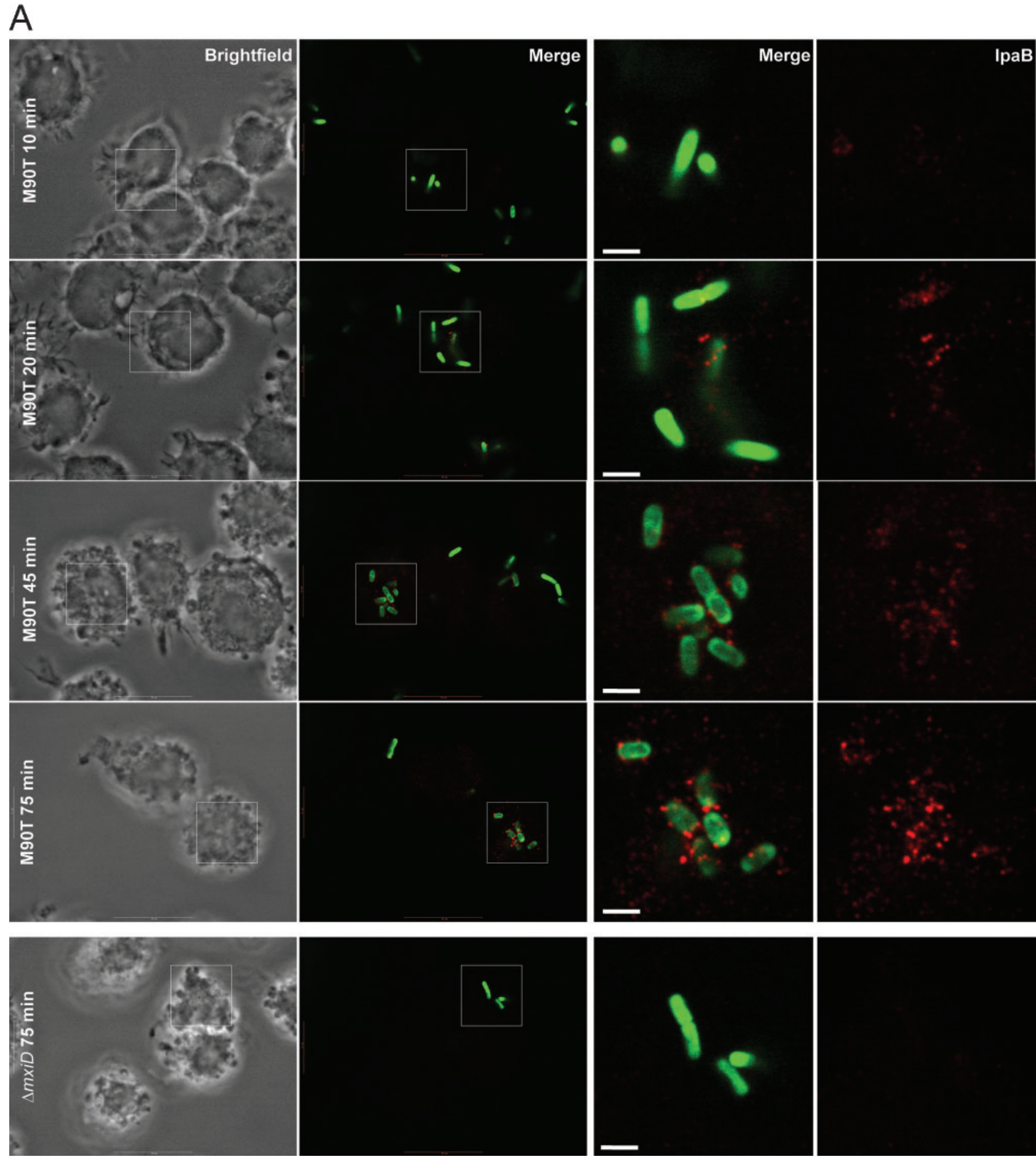

Fig. 1. Intracellular type III secretion of S. flexneri in infected macrophages. J774 macrophages were infected with GFPexpressing S. flexneri wild-type M90T or the secretion-deficient mutant strain $\Delta m x i D$ at an m.o.i. of 20 for 75 min, and at the time points indicated immunofluorescence microscopy was used to visualize $(A)$ the secretion of IpaB or $(B)$ the $I p a B$ pool within S. flexneri. Bars, $2 \mu \mathrm{m}$. To stain IpaB in the bacterial cytosol (B, C), S. flexneri was permeabilized with lysozyme before the immuno-staining with monoclonal IpaB H16 and Cy3-conjugated goat anti-mouse antibodies (red). (C) The amount of cytosolic and surface-bound IpaB present prior to the infection was analysed using exponentially growing wild-type $S$. flexneri immobilized on gelatin-coated coverslips. Bars, $3 \mu \mathrm{m}$. Images are representative of at least three independent experiments. 
B

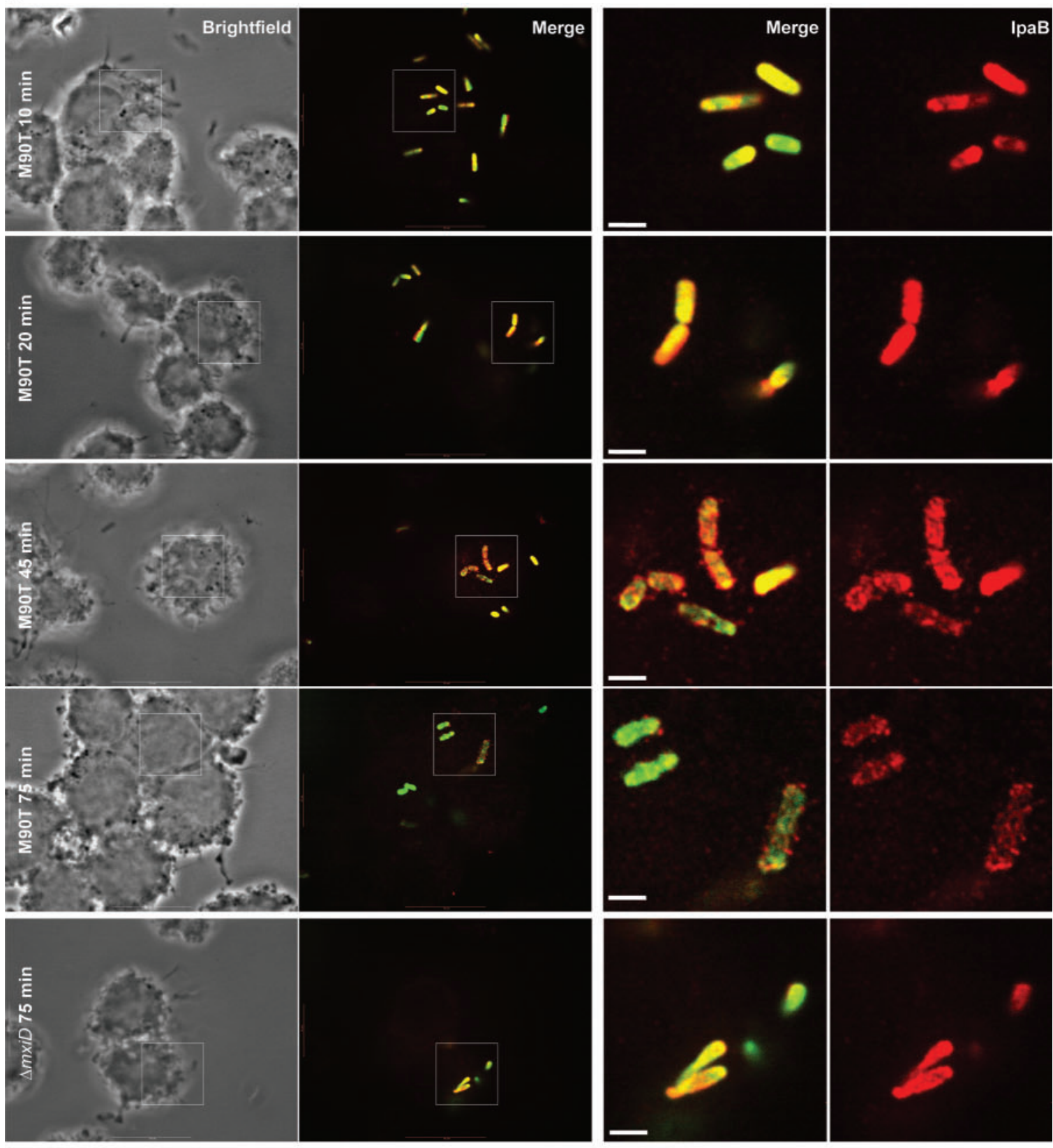

C
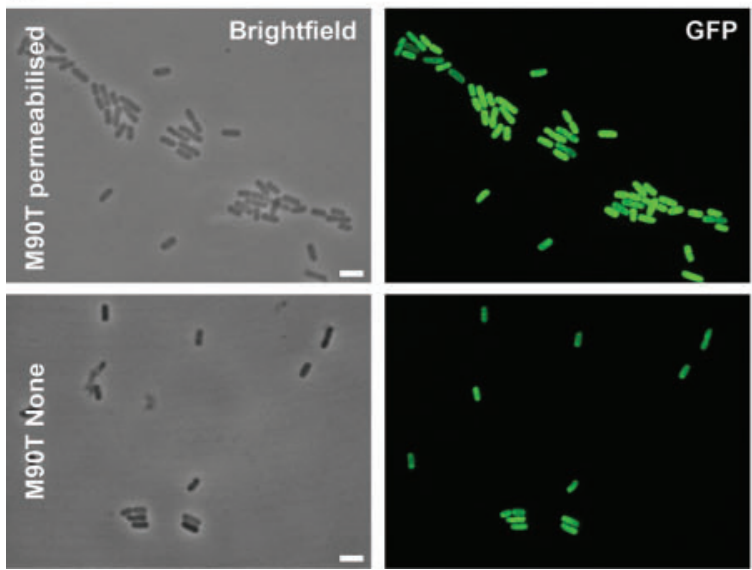
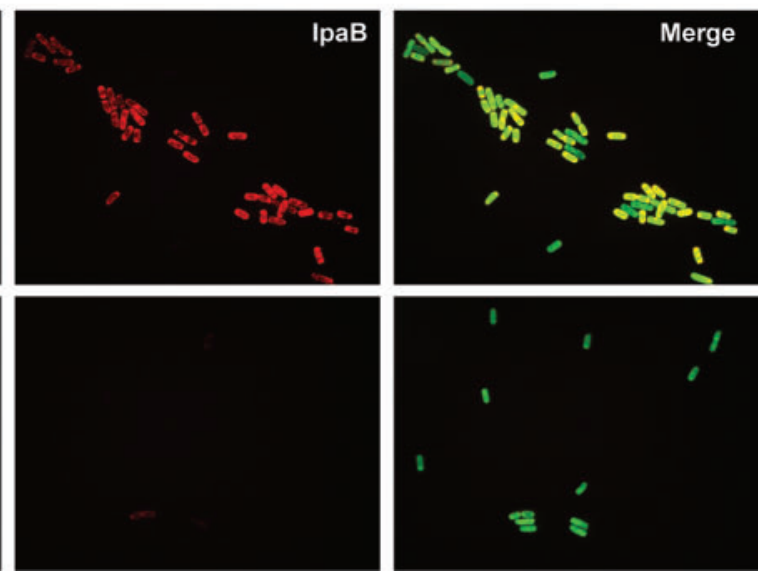
temporal requirement of type III secretion during an infection. To this end, we treated J774 macrophages with $25 \mu \mathrm{M}$ CCCP at different time points prior to, concomitant with, or post-infection with wild-type $S$. flexneri and quantified cytotoxicity by measuring the release of the host-cell enzyme lactate dehydrogenase (LDH). The macrophages were completely protected from $S$. flexneri by CCCP added prior to infection (Fig. 3A), likely due to inhibition of macrophage phagocytosis (see below). Interestingly, however, CCCP added concomitantly with the bacteria or 15-30 min post-infection also abolished $S$. flexneri cytotoxicity, and as long as $60 \mathrm{~min}$ post-infection, the protonophore protected the macrophages to approximately $50 \%$ from Shigella. These findings suggest that the induction of cell death by $S$. flexneri is a continuous process, which can be inhibited by CCCP throughout its course. The inhibition of $S$. flexneri cytotoxicity by CCCP added 15 min post-infection was dose-dependent, and a $70 \%$ reduction in cytotoxicity was observed already at $5 \mu \mathrm{M}$ CCCP (Fig. 3B).

To assay whether $S$. flexneri-triggered macrophage death is specifically inhibited by CCCP, we also tested other reagents that dissipate ion fluxes across biological membranes. We found that cytotoxicity was almost completely blocked by $25 \mu \mathrm{M}$ CCCP but not by other ionophores used at the same concentration (Fig. 3C). Gramicidin (a uniport ionophore selective for monovalent cations) or monensin (a Na${ }^{+} / \mathrm{H}^{+}$antiport ionophore) did not reduce $S$. flexneriinduced cell death significantly (Student's $t$-test; $P=0.21-$ $0.25)$, whereas nigericin $\left(\mathrm{a} \mathrm{K}^{+} / \mathrm{H}^{+}\right.$antiport ionophore) augmented cytotoxicity of $S$. flexneri approximately twofold $(P=0.07)$. The $\mathrm{pH}$-dissipating weak base ammonium chloride $(25 \mathrm{mM})$ and the vacuolar ATPase inhibitor bafilomycin A $(100 \mathrm{nM})$ did not affect S. flexneri cytotoxicity (data not shown). Since CCCP also uncouples oxidative phosphorylation by the mitochondrial $\mathrm{F}_{0} \mathrm{~F}_{1}$ ATPase, we treated $\mathrm{J} 774$ macrophages with the $\mathrm{F}_{0} \mathrm{~F}_{1}$ ATPase inhibitor oligomycin $(12.5 \mu \mathrm{M})$; however, it did not affect $S$. flexneri-triggered cytotoxicity (Fig. 3D). In summary, these results indicate that CCCP but not other reagents that dissipate ion fluxes across membranes inhibits S. flexneri-triggered macrophage death. Moreover, the inhibitory effect of CCCP on S. flexneri-triggered macrophage cytotoxicity was also completely reversible, as demonstrated by washing CCCP-treated macrophages or $S$. flexneri prior to an infection with the bacteria (Fig. 3E). These results indicate that under our conditions the treatment with CCCP killed neither the macrophages nor the bacteria (see also Supplementary Fig. S1).

\section{Effects of CCCP on phagocytosis and phagosomal escape of S. flexneri}

The induction of macrophage cell death by $S$. flexneri occurs in the cytoplasm, requiring that the bacteria are phagocytosed (Zychlinsky et al., 1992) and escape the phagosome (Zychlinsky et al., 1994b). Therefore, the inhibition by CCCP of either phagocytosis and/or T3SSdependent lysis of the phagosomes would be an obvious mechanism to account for protection from Shigella cytotoxicity. The effect of CCCP on phagocytosis and phagosomal escape of S. flexneri wild-type or BS176 was analysed by immunofluorescence microscopy using GFPexpressing S. flexneri strains (Fig. 4A), and uptake or localization within a vacuole was quantified.

The invasive wild-type strain M90T was phagocytosed by J774 macrophages approximately twice as efficiently as the non-invasive derivative BS176 (Fig. 4B; $P=0.07$ ), in agreement with the notion that type III secretion increases the efficiency of phagocytosis of S. flexneri by macrophages (Kuwae et al., 2001). Upon addition of CCCP 15 min or $30 \mathrm{~min}$ post-infection, wild-type $S$. flexneri was still phagocytosed twice as efficiently as BS176 $(P=0.07-0.2)$, and the number of intracellular bacteria of either strain was not altered. These results indicate that under these conditions, neither type III secretion-triggered phagocytosis of strain M90T, nor 'default' phagocytosis of strain BS176 was affected by CCCP. By contrast, in line with the finding that CCCP blocks the Mxi-Spa T3SS in vitro (Fig. 2A), we observed that CCCP added concomitantly with wild-type $S$. flexneri led to a less efficient uptake of wild-type bacteria, which was in the range of the non-invasive strain BS176. Under these conditions, 'default' phagocytosis of strain BS176 was also impaired. Finally, phagocytosis of S. flexneri M90T or BS176 was completely abolished if CCCP was added $30 \mathrm{~min}$ prior to an infection.

To assess the escape of $S$. flexneri from a membrane-bound compartment to the macrophage cytoplasm, we used the late endosomal/lysosomal marker LAMP-1. Approximately $20-30 \%$ of intracellular wild-type S. flexneri was found within a compartment positive for LAMP-1 45 min postinfection, regardless of whether the macrophages were treated with CCCP or not (Fig. 4C). The LAMP-1 staining around wild-type $S$. flexneri was occasionally punctuated, suggesting that the compartment was in the process of being lysed by the bacteria. By contrast, approximately 80 $90 \%$ of the non-invasive S. flexneri strain BS176 localized to LAMP-1-positive compartments, in the absence or presence of CCCP, implying that endocytic trafficking was not affected under these conditions. CCCP blocks intracellular type III secretion (Fig. 2B, C), thus likely preventing type III secretion-dependent lysis of the phagosome. Therefore, it is unexpected that the addition of CCCP 30 min prior to or concomitant with wild-type $S$. flexneri did not result in a larger population of bacteria within LAMP-1-positive vacuoles. Perhaps a residual activity of the T3SS allowed wild-type S. flexneri to escape the phagosomes before they fused with LAMP-1-positive vesicles. In summary, CCCP was found to block phagocytosis, but if added post-infection affected neither the escape of wild-type S. flexneri from a membrane-bound compartment, nor the fusion of Shigella-containing phagosomes with LAMP-1-positive late endosomes and lysosomes. 

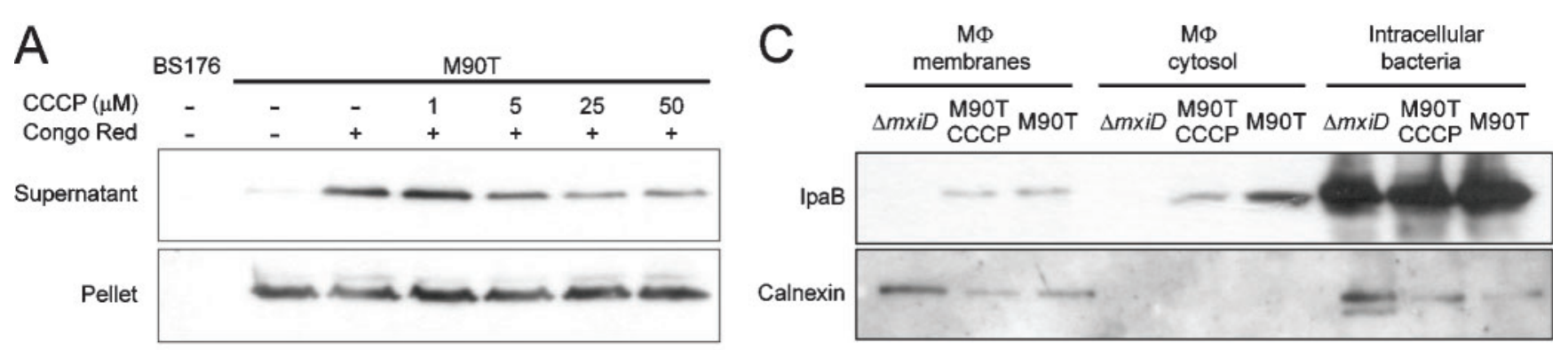

\section{B}
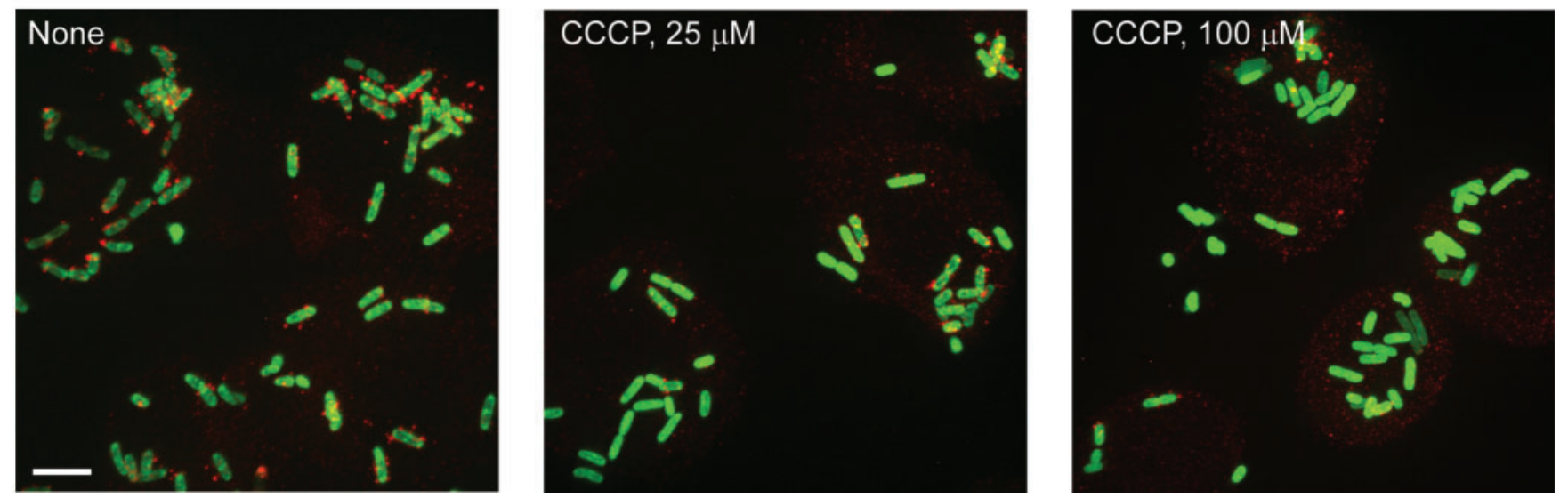

Fig. 2. The protonophore CCCP inhibits type III secretion of S. flexneri triggered by Congo red or in macrophages. (A) Type III secretion of $S$. flexneri wild-type (M90T) was induced with the dye Congo red in vitro after treatment with CCCP at the concentrations indicated, and IpaB in the bacterial supernatant or pellets was determined by Western blotting. (B) Immunofluorescence micrographs of $\mathbf{J 7 7 4}$ macrophages infected for $45 \mathrm{~min}$ with GFP-expressing wild-type S. flexneri (m.o.i. 20 ) in the presence or absence of 25 or $100 \mu \mathrm{M}$ CCCP added 15 min post-infection. Bar, $5 \mu \mathrm{m}$. (C) J774 macrophages were infected (m.o.i. 100) with S. flexneri wild-type (M90T) or $\Delta m x i D$ in the presence or absence of $25 \mu \mathrm{M}$ CCCP added 15 min post-infection. At 45 min post-infection, lysates of the infected macrophages were fractionated by centrifugation into bacteria/ macrophage debris ('Intracellular bacteria') or macrophage (MФ) cytosol and membranes, respectively. S. flexneri lpaB and the endoplasmic reticulum membrane protein calnexin were detected by Western blotting. Similar results were obtained in four (A,

C) or three (B) independent experiments.

\section{Activation of caspase-1 and maturation of IL-1 $\beta$ are inhibited by CCCP}

Caspase-1 is required for the induction of rapid macrophage cell death by $S$. flexneri (Hilbi et al., 1998) and upon activation cleaves pro-IL-1 $\beta$ to its mature form ( $\mathrm{Li}$ et al., 1995). Since CCCP added post-infection to S. flexneriinfected macrophages did not affect bacterial uptake and lysis of the phagosome, we determined whether CCCP inhibits the processing and activation of caspase- 1 and proIL-1 $\beta$. J774 macrophages were infected with S. flexneri, and activation of caspase- 1 was assayed by flow cytometry using the fluorogenic caspase-1 substrate FLICA. Activation of caspase- 1 by the wild-type strain M90T was blocked in a dose-dependent manner by the addition of $25 \mu \mathrm{M}$ or $100 \mu \mathrm{M}$ CCCP $15 \mathrm{~min}$ post-infection (Fig. 5A). By contrast, an infection with the type III secretion-deficient strain $\Delta m x i D$ did not result in activation of caspase-1 above background level, and the addition of CCCP had no effect. As expected, the activation of caspase-1 in $S$. flexneri-infected macrophages was inhibited by peptide inhibitors of caspase-1 (YVAD-cmk; Chen et al., 1996; Hilbi et al., 1997, 1998) or TPPII (AAF-cmk; Hilbi et al., 2000), respectively.

The effect of CCCP on maturation of pro-IL-1 $\beta$ was analysed by Western blotting using thioglycollate-elicited mouse peritoneal macrophages. In macrophages infected with wild-type $S$. flexneri, maturation of the $31 \mathrm{kDa}$ proIL- $1 \beta$ to its $18 \mathrm{kDa}$ active form was visible as early as 30 min post-infection (Fig. $5 \mathrm{~B}$ ), indicating that caspase-1 was activated, as observed previously (Hilbi et al., 1997; Zychlinsky et al., 1994a). Treatment of macrophages with $25 \mu \mathrm{M}$ CCCP $30 \mathrm{~min}$ before or $15 \mathrm{~min}$ after infection with wild-type strain M90T inhibited the maturation of pro-IL$1 \beta$, indicating that the activation of caspase- 1 was blocked under these conditions. As expected, the virulenceplasmid-cured strain BS176 did not cause any maturation of pro-IL- $1 \beta$ in the absence or presence of CCCP, and the expression of pro-IL- $1 \beta$ was induced by LPS. 

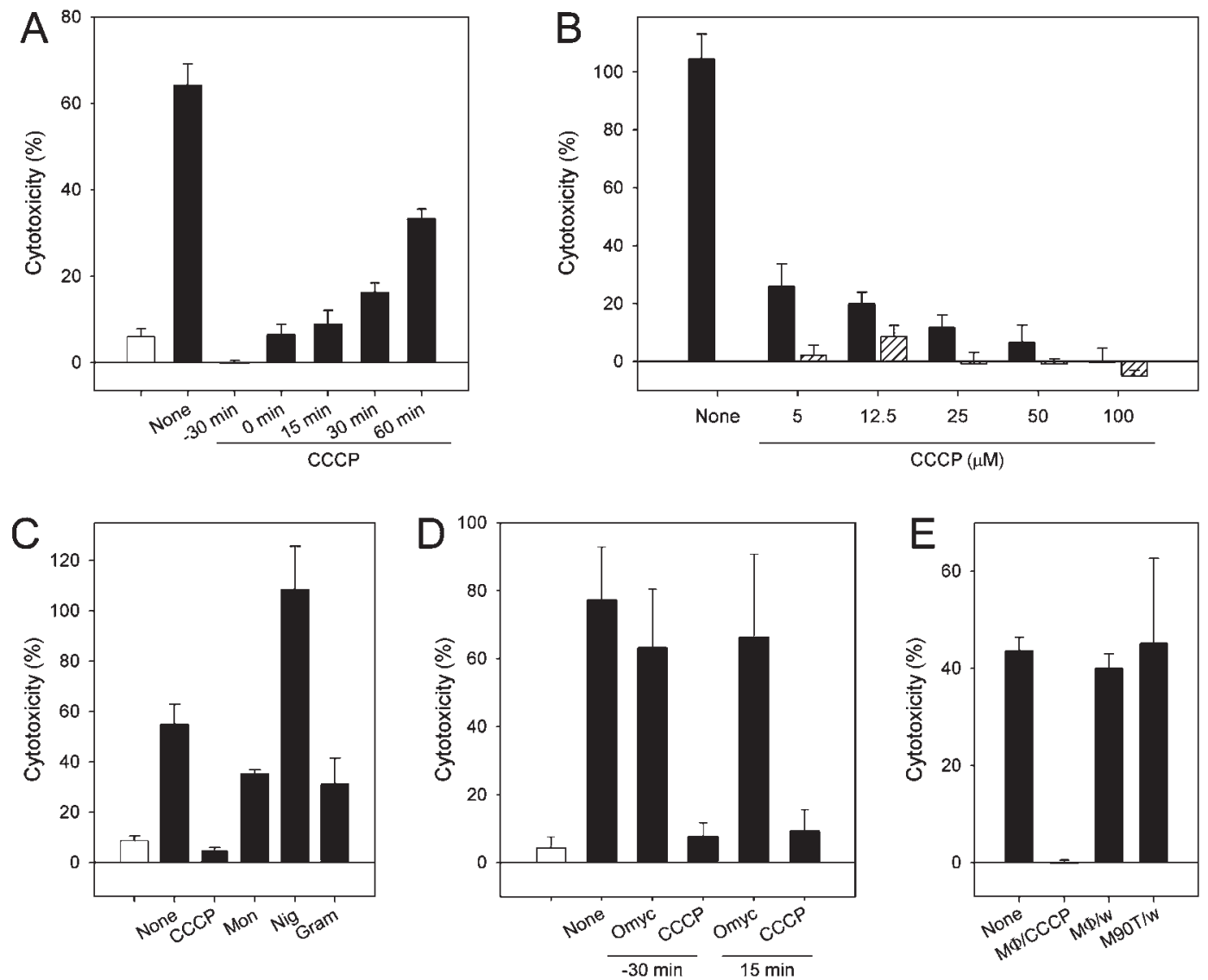

Fig. 3. S. flexneri-induced macrophage death is specifically blocked by the protonophore CCCP. J774 macrophages were infected with S. flexneri wild-type strain M90T (black bars), the virulence-plasmid-cured strain BS176 (white bars) or the secretion-deficient mutant $\Delta m x i D$ (hatched bars) at an m.o.i. of 50, and (A) $25 \mu \mathrm{M}$ CCCP was added at time points indicated prior to, concomitant with or after infection, (B) different concentrations of CCCP were added 15 min after infection, (C) the cells were treated with the indicated ionophores $(25 \mu \mathrm{M})$ at 30 min prior to infection, or $(D)$ the cells were treated with $12.5 \mu \mathrm{M}$ oligomycin or $25 \mu \mathrm{M} \mathrm{CCCP}$ at the indicated time points. (E) Reversibility of the CCCP effect was analysed by treating $S$. flexneri M90T or macrophages (MФ) with $25 \mu \mathrm{M} \mathrm{CCCP} \mathrm{for} 30 \mathrm{~min}$ followed by a wash step (/w) to remove the inhibitor prior to the infection. Cytotoxicity was determined by LDH release $2 \mathrm{~h} 30$ min post-infection. The data shown are means and standard deviation of triplicates. Similar results were obtained in at least three independent experiments $(P<0.01$, unless stated otherwise in the text).

\section{CCCP does not affect ATP-triggered caspase-1 activation or staurosporine-induced apoptosis}

To address the question whether CCCP specifically blocks S. flexneri-induced activation of caspase-1 and macrophage apoptosis, we analysed the apoptotic pathways triggered by ATP and staurosporine. Caspase-1 is activated in the course of the apoptotic pathway induced by ATP by engaging $\mathrm{P}_{2} \mathrm{X}_{7}$ receptors (Hogquist et al., 1991; Mariathasan et al., 2006; Perregaux \& Gabel, 1994), yet caspase-1 is not required for the induction of this apoptotic pathway (Li et al., 1995). Exposure of LPS-activated J774 macrophages to $1 \mathrm{mM}$ ATP-activated caspase- 1 as determined by flow cytometry using the fluorogenic caspase-1 substrate FLICA (Fig. 6A). The activation of caspase-1 triggered by ATP was not inhibited by $100 \mu \mathrm{M}$ CCCP, but it was inhibited by $50 \mu \mathrm{M}$ AAF-cmk, as reported previously (Hilbi et al., 2000), suggesting that the protonophore does not target the activation of caspase-1 per se.

The apoptotic pathway induced by the protein kinase C inhibitor staurosporine involves mitochondria but not caspase-1 (Jacobsen et al., 1996). Cytotoxicity triggered by $1 \mu \mathrm{M}$ staurosporine in $\mathrm{J774}$ macrophages was not affected by 25 or $50 \mu \mathrm{M}$ CCCP and was inhibited to only approximately $50 \%$ by $100 \mu \mathrm{M}$ CCCP (Fig. 6B). This experiment also showed that treatment with $25-100 \mu \mathrm{M}$ CCCP for a prolonged time $(9 \mathrm{~h})$ was barely cytotoxic for J774 macrophages (5-10\% LDH release, data not shown), similar to what has been reported for other cells (Linsinger et al., 1999; Matsuyama et al., 2000). In summary, the above results indicate that CCCP specifically blocks $S$. 


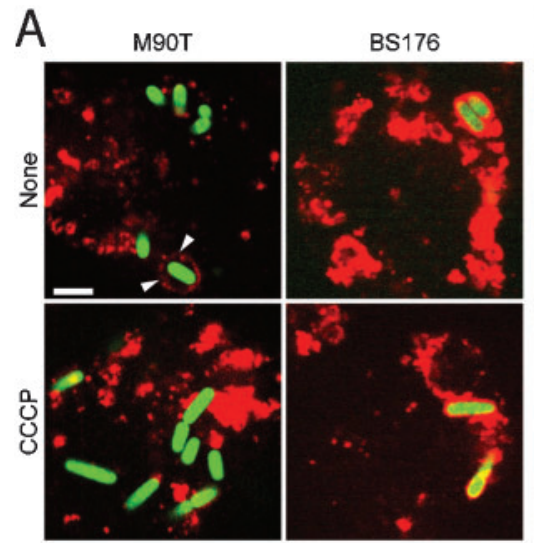

B
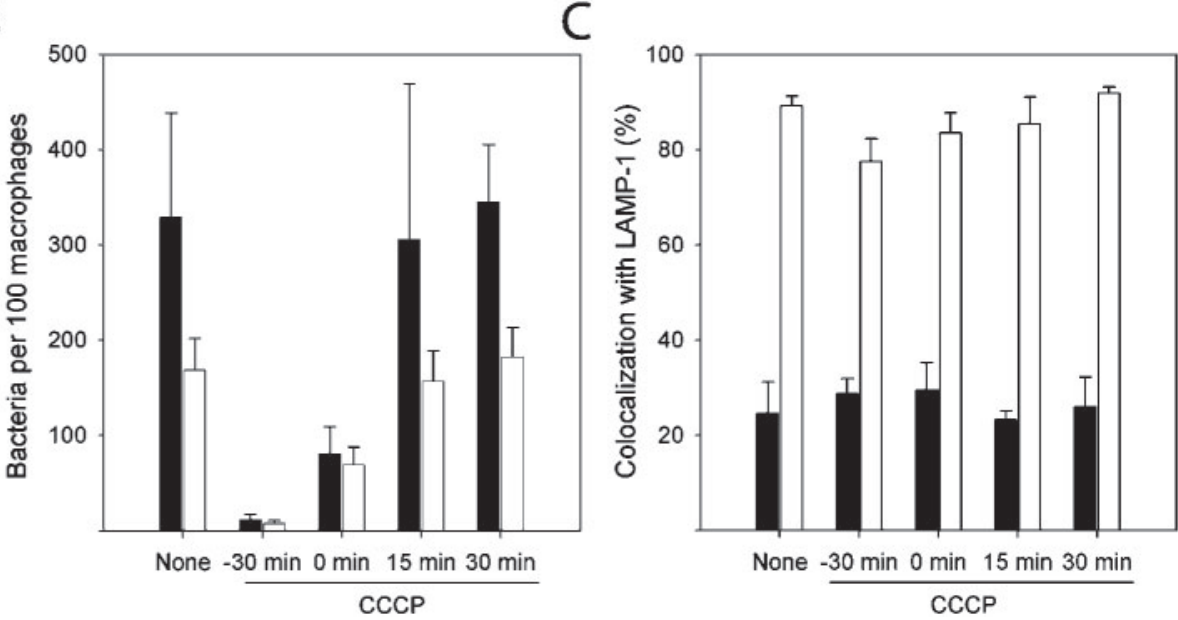

Fig. 4. Effects of CCCP on phagocytosis and phagosomal escape of S. flexneri. J774 macrophages were infected with GFPexpressing S. flexneri wild-type M90T (black bars) or virulence-plasmid-cured BS176 (white bars) at an m.o.i. of 20 in the presence or absence of $25 \mu \mathrm{M}$ CCCP added 15 min post-infection (A) or at the indicated time points prior to, concomitant with or after infection $(B, C)$. At 45 min post-infection, the macrophages were immuno-stained for the late endosomal/lysosomal marker LAMP-1, and fluorescence microscopy was used to quantify (B) phagocytosis and (C) localization of the bacteria (green) in LAMP-1-positive vacuoles (red). The data shown represent the mean and standard deviation of three independent experiments. Bar, $2 \mu \mathrm{m}$.

flexneri-triggered, type III secretion-dependent macrophage cell death but not other apoptotic pathways.

\section{Expression of plasmid-encoded IpaB increases cytotoxicity of wild-type S. flexneri}

The S. flexneri effector IpaB is intracellularly secreted by the T3SS during an infection of macrophages with bacteria. To test whether expression of plasmid-encoded IpaB during an infection affects cytotoxicity of $S$. flexneri, IpaB was cloned under the control of an arabinose-inducible promoter. The addition of arabinose to $S$. flexneri growing exponentially for 2-2.5 h or to bacteria concomitant with an infection complemented a $\triangle i p a B$ mutant strain, but did not increase cytotoxicity of a type III secretion-deficient strain $(\Delta m x i D)$ (Fig. 7A). Upon induction of IpaB in wild-type S. flexneri M90T prior to or concomitant with an infection, bacterial cytotoxicity was increased $(P=0.01-0.02)$. To assess the level of endogenous and arabinose-induced IpaB in the $S$. flexneri strains, we analysed the expression and Congo redtriggered secretion of IpaB by Western blotting. While arabinose-dependent expression of IpaB was readily observed in the $\triangle i p a B$ mutant strain, the total amount of produced and secreted IpaB did not increase beyond the level of endogenous IpaB present in wild-type strain M90T or $\Delta m x i D$ (Fig. 7B). A possible explanation for these observations is that the endogenous chaperone $\operatorname{IpgC}$ is limiting the amount of IpaB stored in the bacteria (Schuch et al., 1999). However, even as the total amount of endogenously produced $\mathrm{IpaB}$ is apparently not increased by an induction of plasmid-encoded IpaB prior to the infection, continuous replenishment of the bacterial IpaB pool upon induction might allow more IpaB to be secreted, thus promoting cytotoxicity of $S$. flexneri.

\section{DISCUSSION}

In this study we analysed the temporal requirement of type III secretion to trigger macrophage apoptosis by $S$. flexneri. The type III-secreted translocator/effector protein IpaB was found to be secreted within macrophages for at least 75 min (Fig. 1), which is considerably after the completion of bacterial uptake and escape from the phagosome (Fig. 4). Interestingly, IpaB accumulates in 'patches' on the bacterial surface throughout the secretion process (Figs $1 \mathrm{~A}$ and $2 \mathrm{~B}$ ), and the secreted protein shows a punctate rather than a homogeneous distribution pattern in the macrophage cytoplasm, as observed previously (Thirumalai et al., 1997). This localization and architecture of IpaB aggregates might be relevant for the activation of caspase-1 by IpaB, which is a hallmark of $S$. flexneri-triggered macrophage death. Previously, it has been shown that in vitro IpaB directly binds caspase-1 (Chen et al., 1996; Hilbi et al., 1997, 1998; Guichon et al., 2001) and in infected macrophages partially co-localizes with activated caspase1 on the bacterial surface or host-cell membranes, and in the cytoplasm (Schroeder \& Hilbi, 2006).

The protonophore CCCP efficiently blocked type III secretion of $S$. flexneri and cell death in infected macrophages, even if added post-infection (Figs 2B, C, 3A, B), suggesting that after escape of $S$. flexneri from the 

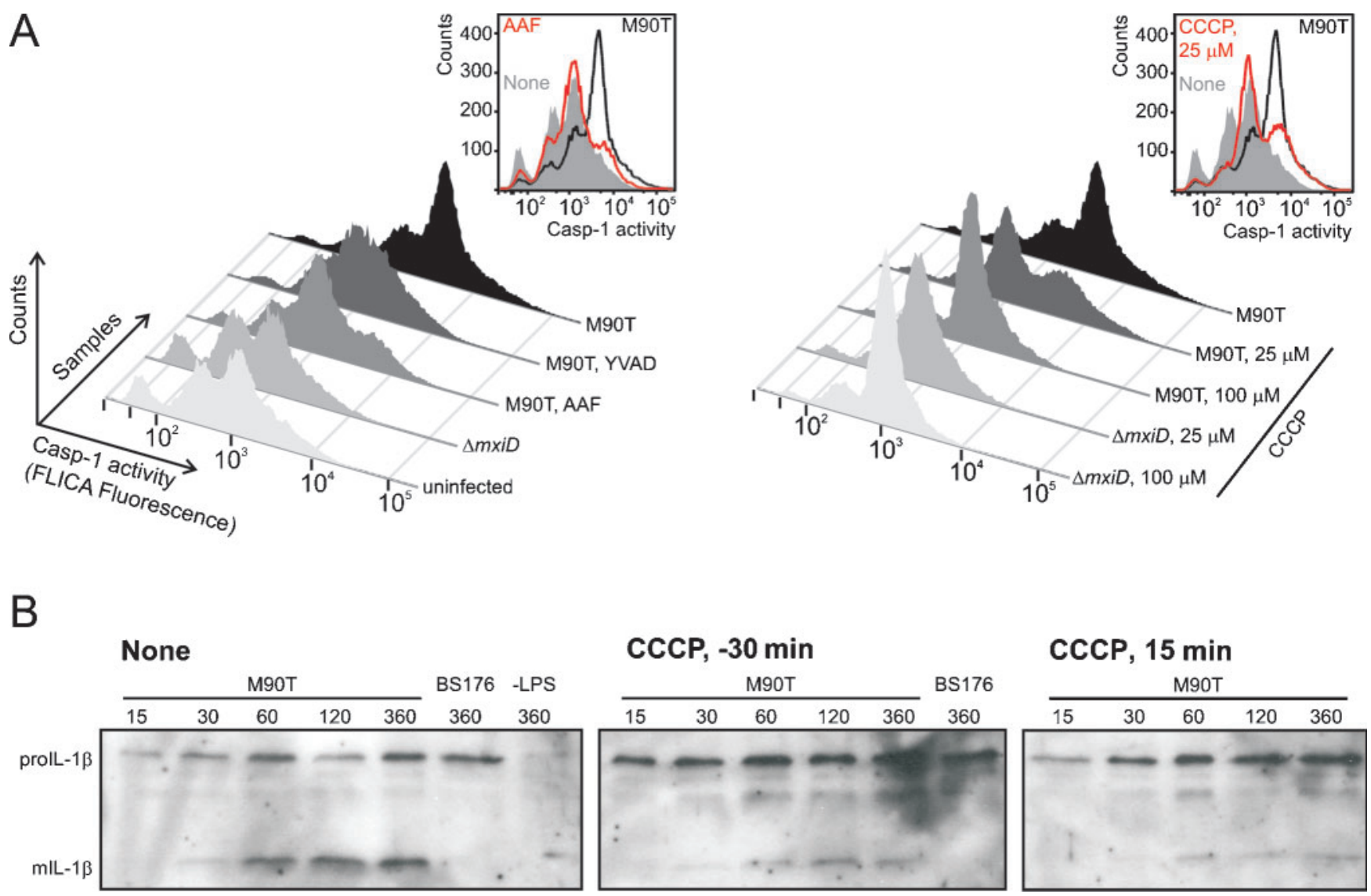

Fig. 5. Activation of caspase- 1 and maturation of IL-1 $\beta$ is inhibited by CCCP. (A) J774 macrophages were infected with wild-type $S$. flexneri M90T or the type III secretion-deficient mutant $\Delta m x i D$ at an m.o.i. of 50 in the presence or absence of YVAD-cmk $(100 \mu \mathrm{M})$ or AAF-cmk $(50 \mu \mathrm{M})$ added 30 min prior to the infection, or CCCP $(25 \mu \mathrm{M}, 100 \mu \mathrm{M})$ added 15 min postinfection. Activated caspase-1 was stained with FLICA and analysed by flow cytometry 100 min after infection. (B) The maturation of IL-1 $\beta$ was analysed by Western blotting in mouse thioglycollate-elicited peritoneal macrophages infected with wild-type S. flexneri or virulence-plasmid-cured BS176 (m.o.i. 50). The macrophages were activated overnight with LPS and mock-treated or treated with $25 \mu \mathrm{M}$ CCCP 15 min post-infection. Similar results were obtained in three independent experiments.

phagosome, prolonged type III secretion in the macrophage cytoplasm is required for maximum induction of cell death. In line with these findings, the Mxi-Spa T3SS is functionally required after initial invasion of epithelial cells, and effector proteins are present in the bacterial cytoplasm prior to and after uptake by these cells (Ménard et al., 1994a; Page et al., 1999; Rathman et al., 2000; Schuch et al., 1999). To study a role for IpaB, IpaC and their chaperone IpgC post-invasion, the $i p a B$, ipaC, or $i p g C$ genes were expressed under the control of the IPTGinducible lac promoter in the corresponding mutant strains (Page et al., 1999). In this system, S. flexneri grown in the presence of IPTG entered epithelial cells at wild-type level, but upon removal of IPTG after uptake, the bacteria were defective for plaque formation in a cell monolayer. Thus, $\mathrm{IpaB}, \mathrm{IpaC}$ as well as IpgC are required for intercellular dissemination, in particular for the lysis of the protrusion membranes during cell-to-cell spread. In a related approach, the requirement of type III secretion postinvasion was demonstrated by a system termed TIER (test of intracellular expression requirements) (Schuch et al., 1999). Here, specific loci were transiently expressed under the control of an arabinose-inducible promoter in the corresponding mutant strains, followed by infection of an epithelial cell monolayer in a glucose-rich medium repressing the genes. Using this approach, structural components of the T3SS (MxiM, Spa33), secreted effectors (IpaB, IpaC and IpaD), as well as regulatory elements (VirF, VirB) were found to be required for the escape of $S$. flexneri from protrusion-derived double-membrane vesicles. Finally, in a fluorescence-activated cell sorter (FACS)based screen for mutants defective in intercellular spread, components of the T3SS were also identified (Rathman et al., 2000). In summary, after the initial uptake by epithelial cells, as well as within macrophages, the Mxi-Spa T3SS is required for further interactions of S. flexneri with 

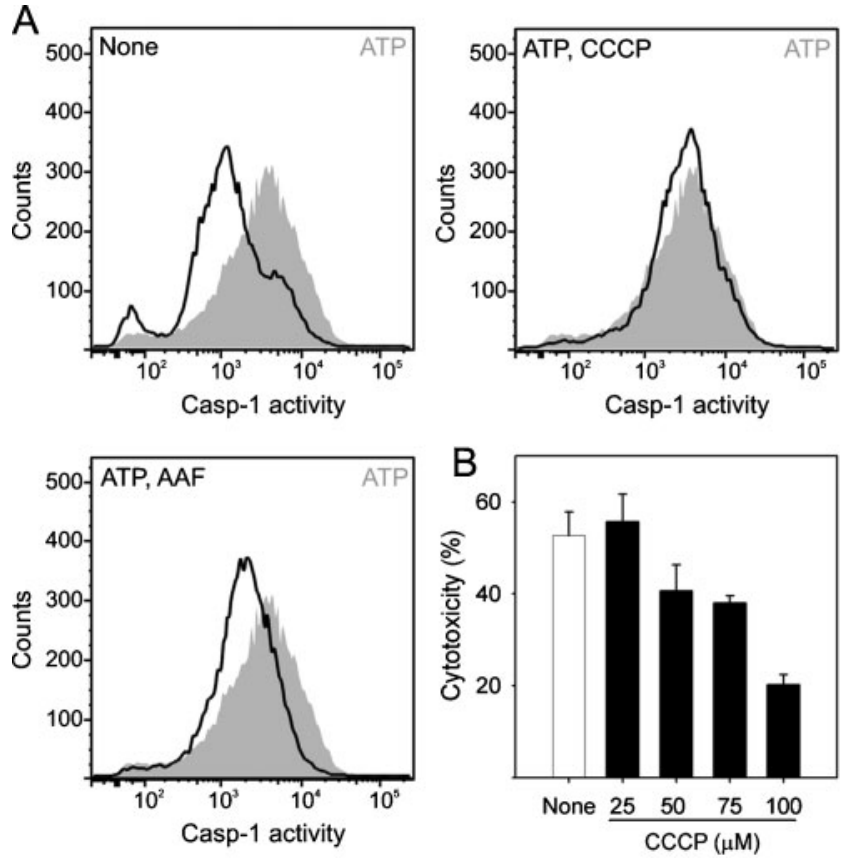

Fig. 6. CCCP does not affect ATP-triggered caspase-1 activation or staurosporine-induced apoptosis. (A) LPS-activated J774 macrophages were incubated with $1 \mathrm{mM}$ ATP in the presence or absence of $100 \mu \mathrm{M}$ CCCP added 30 min after or $50 \mu \mathrm{M}$ AAFcmk added 30 min prior to ATP. Activated caspase- 1 was stained with FLICA and analysed by flow cytometry 90 min after incubation with ATP. (B) J774 macrophages were treated with the indicated concentrations of CCCP (black bars) 30 min prior to an incubation with $1 \mu \mathrm{M}$ staurosporine. At $9 \mathrm{~h}$ after the addition of staurosporine, cytotoxicity was determined by LDH release. The data shown are representative of three independent experiments.

its host cells. During cell-to-cell spread the contact with the protrusion membrane likely triggers type III secretion. By contrast, the factor triggering type III secretion in the macrophage cytoplasm is currently unknown.

Type III secretion by S. flexneri (Enninga et al., 2005) and Salmonella enterica serovar Typhimurium (Schlumberger et al., 2005) was recently analysed on a single-cell level in real time using time-lapse fluorescence microscopy. In these studies, the depletion of tetracysteine-tagged $S$. flexneri effectors (IpaB, IpaC) labelled with a fluoresceinconjugated biarsenical dye was analysed, or the depletion of Sal. typhimurium effectors (SipA, SopE) and the recruitment of the cognate GFP-tagged chaperone InvB to secretion foci was quantified. Upon host-cell contact, type III secretion was found to be initiated within 10-90 s and to proceed until the entire pool of type III-secreted effectors is released within minutes. These results do not necessarily conflict with our finding that type III secretion in the macrophage cytoplasm proceeds for more than $1 \mathrm{~h}$ post-infection. Our findings might (i) point to differences between the host cells used, i.e. macrophages vs epithelial cells, (ii) indicate that a subset of S. flexneri triggers type III
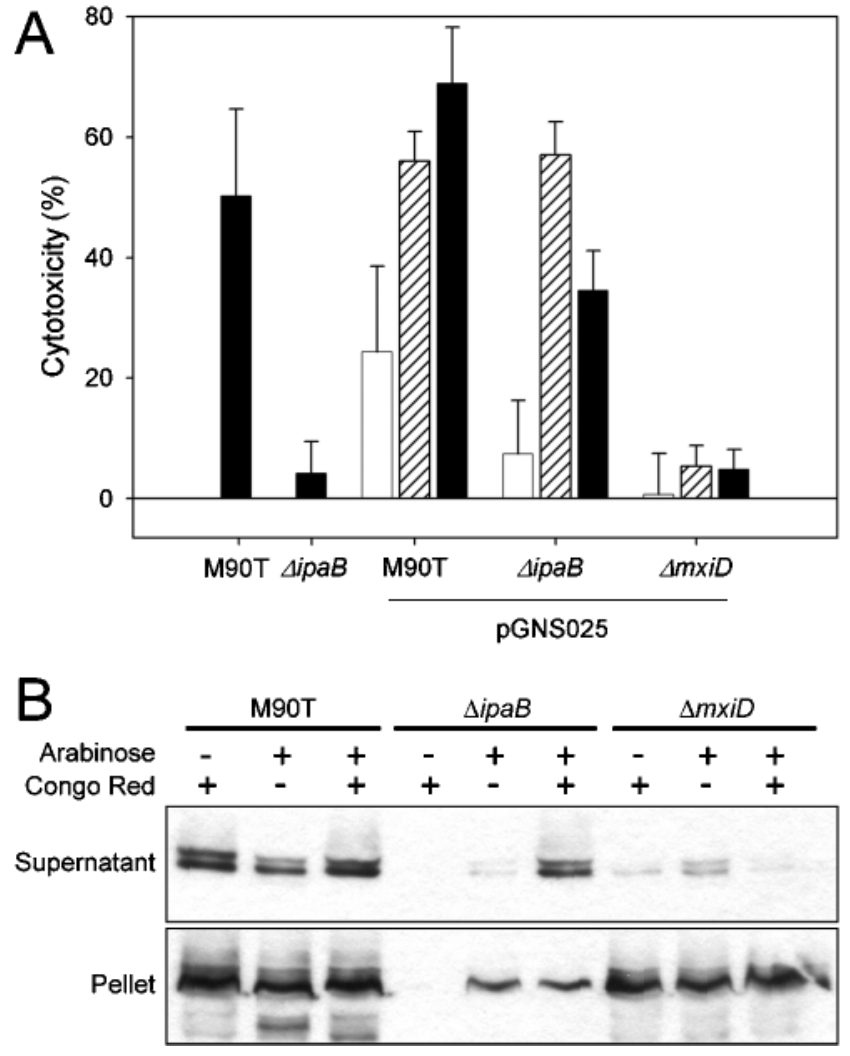

Fig. 7. Expression of IpaB from a plasmid increases cytotoxicity of wild-type S. flexneri. (A) J774 macrophages were infected with wild-type $S$. flexneri M90T, the non-polar ipaB deletion mutant $\triangle i p a B$ or the secretion-deficient mutant $\Delta m x i D$ (m.o.i. 50) carrying the arabinose-inducible IpaB expression plasmid pGNS025 where indicated. The strains were grown without arabinose (white bars), or in the presence of $0.1 \%$ arabinose added to the subculture prior to (hatched white bars) or concomitant with (black bars) an infection. Cytotoxicity was measured by LDH release 2 h 45 min post-infection. The data shown are means and standard deviation of triplicates. (B) To control expression and secretion of IpaB produced by pGNS025, subcultures of the $S$. flexneri strains M90T, $\triangle i p a B$ or $\triangle m x i D$ carrying the IpaB expression plasmid were grown in the presence or absence of $0.1 \%$ arabinose. Type III secretion was induced with the dye Congo red, and the amount of IpaB in the supernatant or in bacterial pellets was determined by Western blotting. Similar results were obtained in two $(A)$ or four (B) independent experiments.

secretion only after phagocytosis by macrophages, (iii) suggest that de novo expression and translocation of cytotoxic type III-secreted effector proteins continue after the bacteria reached the macrophage cytoplasm, and/or (iv) indicate that type III secretion is not the rate-limiting step in the kinetics of cell-death induction by $S$. flexneri.

CCCP has been widely used as an uncoupling and energydepleting reagent. However, within the time frame of the experiments described here, CCCP is not cytotoxic for 
macrophages (Fig. 3E, 6B) or other cells, and the cellular ATP pool presumably does not change significantly (Linsinger et al., 1999; Matsuyama et al., 2000). Accordingly, CCCP did not block ATP-dependent processes such as endocytosis and the formation of LAMP-1positive phagolysosomes (Fig. 4A, C). On the other hand, CCCP inhibited macrophage phagocytosis (Fig. 4B). Furthermore, CCCP uncouples oxidative phosphorylation in mitochondria, raising the possibility that the destruction of mitochondrial integrity by the protonophore contributes to the inhibition of $S$. flexneri cytotoxicity. However, mitochondria do not seem to be involved in the initiation of S. flexneri-induced cell death, since (i) both CCCP and the $\mathrm{F}_{0} \mathrm{~F}_{1}$ ATPase inhibitor oligomycin abolish mitochondrial function, yet only CCCP inhibits $S$. flexneri-induced macrophage cell death (Fig. 3D), (ii) CCCP at concentrations sufficient to abolish S. flexneri-triggered apoptosis did not inhibit mitochondria-dependent apoptosis induced by staurosporine (Fig. 6B), (iii) anti-apoptotic proteins targeting the mitochondrial death pathway (Bcl-2, Bcl$\mathrm{X}_{\mathrm{L}}$ ) do not protect macrophages from S. flexneri (Hilbi et al., 1998), and (iv) during S. flexneri-triggered caspase-1dependent macrophage cell death, the prototypic effector caspase-3 of mitochondrial apoptosis is neither required (Hilbi et al., 1998) nor activated, as its substrate poly-ADPribose polymerase (PARP) is not cleaved (Chen et al., 1996). While mitochondria are not required to trigger $S$. flexneri-induced macrophage cell death, virulent $S$. flexneri causes damage to these organelles in infected human monocyte-derived macrophages (Koterski et al., 2005). Mitochondrial damage triggers the intrinsic apoptotic pathway, which thus in turn might contribute to $S$. flexneri-induced macrophage death.

Phagosome acidification also does not seem to play a role in cell-death induction by $S$. flexneri and protection thereof, since among several ionophores tested only the protonophore CCCP inhibited S. flexneri-induced cell death (Fig. 3C), while a number of other reagents that also dissipate the $\mathrm{pH}$ gradient of acidic phagolysosomes do not affect cell death. These chemicals include the cation uniport ionophore gramicidin $\mathrm{A}$, the $\mathrm{Na}^{+} / \mathrm{H}^{+}$antiport ionophore monensin, the lysosomotropic weak base ammonium chloride, and the vacuolar ATPase inhibitor bafilomycin A. The $\mathrm{K}^{+} / \mathrm{H}^{+}$antiport ionophore nigericin even increased Shigella cytotoxicity approximately twofold. This result corresponds to reports that nigericin and other treatments leading to potassium depletion in macrophages trigger apoptosis and the release of mature IL- $1 \beta$ by activating caspase-1 (Cheneval et al., 1998; Perregaux \& Gabel, 1994; Walev et al., 1995). Thus, in S. flexneriinfected macrophages treated with nigericin, the bacteria and the ionophore seem to synergistically activate caspase1 and cell death. The observation that dissipation of the phagolysosomal $\mathrm{pH}$ gradient did not inhibit $S$. flexneri cytotoxicity indicates that the $\mathrm{pH}$ gradient is also not required for phagosomal escape, which is a prerequisite for cytotoxicity of S. flexneri (Zychlinsky et al., 1994b). This result is in agreement with an early report showing that the escape of $S$. flexneri from phagosomes of epithelial cells is a $\mathrm{pH}$-independent process (Finlay \& Falkow, 1988). In summary, under the experimental conditions used, the inhibition of S. flexneri type III secretion by CCCP (Fig. 2) seems to account preferentially if not exclusively for the inhibition of $S$. flexneri cytotoxicity towards macrophages.

\section{ACKNOWLEDGEMENTS}

We would like to thank Wolf-Dietrich Hardt and his group for constructive criticism and assistance with laser confocal microscopy. This work was supported by grants from the Swiss National Science Foundation (631-065952) and the ETH Zürich (TH 17/02-3).

\section{REFERENCES}

Allaoui, A., Sansonetti, P. J. \& Parsot, C. (1993). MxiD: an outer membrane protein necessary for the secretion of the Shigella flexneri Ipa invasins. Mol Microbiol 7, 59-68.

Bahrani, F. K., Sansonetti, P. J. \& Parsot, C. (1997). Secretion of Ipa proteins by Shigella flexneri: inducer molecules and kinetics of activation. Infect Immun 65, 4005-4010.

Barzu, S., Nato, F., Rouyre, S., Mazie, J.-C., Sansonetti, P. J. \& Phalipon, A. (1993). Characterization of B-cell epitopes on IpaB, an invasion-associated antigen of Shigella flexneri: identification of an immunodominant domain recognized during natural infection. Infect Immun 61, 3825-3831.

Blocker, A., Gounon, P., Larquet, E., Niebuhr, K., Cabiaux, V., Parsot, C. \& Sansonetti, P. (1999). The tripartite type III secreton of Shigella flexneri inserts IpaB and IpaC into host membranes. J Cell Biol 147, 683-693.

Blocker, A., Jouihri, N., Larquet, E., Gounon, P., Ebel, F., Parsot, C., Sansonetti, P. \& Allaoui, A. (2001). Structure and composition of the Shigella flexneri "needle complex", a part of its type III secreton. Mol Microbiol 39, 652-663.

Buchrieser, C., Glaser, P., Rusniok, C., Nedjari, H., D’Hauteville, H., Kunst, F., Sansonetti, P. \& Parsot, C. (2000). The virulence plasmid pWR100 and the repertoire of proteins secreted by the type III secretion apparatus of Shigella flexneri. Mol Microbiol 38, 760-771.

Chen, Y., Smith, M. R., Thirumalai, K. \& Zychlinsky, A. (1996). A bacterial invasin induces macrophage apoptosis by directly binding ICE. EMBO J 15, 3853-3860.

Cheneval, D., Ramage, P., Kastelic, T., Szelestenyi, T., Niggli, H., Hemmig, R., Bachmann, M. \& MacKenzie, A. (1998). Increased mature interleukin-1 $\beta$ (IL-1 $\beta$ ) secretion from THP-1 cells induced by nigericin is a result of activation of p45 IL- $1 \beta$-converting enzyme processing. J Biol Chem 273, 17846-17851.

Cornelis, G. R. (2006). The type III secretion injectisome. Nat Rev Microbiol 4, 811-825.

Cossart, P. \& Sansonetti, P. J. (2004). Bacterial invasion: the paradigms of enteroinvasive pathogens. Science 304, 242-248.

De Geyter, C., Vogt, B., Benjelloun-Touimi, Z., Sansonetti, P. J., Ruysschaert, J. M., Parsot, C. \& Cabiaux, V. (1997). Purification of IpaC, a protein involved in entry of Shigella flexneri into epithelial cells and characterization of its interaction with lipid membranes. FEBS Lett 400, 149-154.

De Geyter, C., Wattiez, R., Sansonetti, P., Falmagne, P., Ruysschaert, J. M., Parsot, C. \& Cabiaux, V. (2000). Characterization of the interaction of IpaB and IpaD, proteins required for entry of Shigella 
flexneri into epithelial cells, with a lipid membrane. Eur J Biochem 267, 5769-5776.

Enninga, J., Mounier, J., Sansonetti, P. \& Tran Van Nhieu, G. (2005). Secretion of type III effectors into host cells in real time. Nat Methods 2, 959-965.

Espina, M., Olive, A. J., Kenjale, R., Moore, D. S., Ausar, S. F., Kaminski, R. W., Oaks, E. V., Middaugh, C. R., Picking, W. D. \& Picking, W. L. (2006). IpaD localizes to the tip of the type III secretion system needle of Shigella flexneri. Infect Immun 74, 4391-4400.

Finlay, B. B. \& Falkow, S. (1988). Comparison of the invasion strategies used by Salmonella cholera-suis, Shigella flexneri and Yersinia enterocolitica to enter cultured animal cells: endosome acidification is not required for bacterial invasion or intracellular replication. Biochimie 70, 1089-1099.

Galan, J. E. \& Wolf-Watz, H. (2006). Protein delivery into eukaryotic cells by type III secretion machines. Nature 444, 567-573.

Guichon, A., Hersh, D., Smith, M. R. \& Zychlinsky, A. (2001). Structure-function analysis of the Shigella virulence factor IpaB. J Bacteriol 183, 1269-1276.

Guzman, L. M., Belin, D., Carson, M. J. \& Beckwith, J. (1995). Tight regulation, modulation, and high-level expression by vectors containing the arabinose pBAD promoter. J Bacteriol 177, 4121-4130.

Haimovich, B. \& Venkatesan, M. M. (2006). Shigella and Salmonella: death as a means of survival. Microbes Infect 8, 568-577.

Hayward, R. D., Cain, R. J., McGhie, E. J., Phillips, N., Garner, M. J. \& Koronakis, V. (2005). Cholesterol binding by the bacterial type III translocon is essential for virulence effector delivery into mammalian cells. Mol Microbiol 56, 590-603.

Hilbi, H. (2006). Modulation of phosphoinositide metabolism by pathogenic bacteria. Cell Microbiol 8, 1697-1706.

Hilbi, H., Chen, Y., Thirumalai, K. \& Zychlinsky, A. (1997). The interleukin $1 \beta$-converting enzyme, caspase 1 , is activated during Shigella flexneri-induced apoptosis in human monocyte-derived macrophages. Infect Immun 65, 5165-5170.

Hilbi, H., Moss, J. E., Hersh, D., Chen, Y., Arondel, J., Banerjee, S., Flavell, R. A., Yuan, J., Sansonetti, P. J. \& Zychlinsky, A. (1998), Shigella-induced apoptosis is dependent on caspase-1 which binds to IpaB. J Biol Chem 273, 32895-32900.

Hilbi, H., Puro, R. J. \& Zychlinsky, A. (2000). Tripeptidyl peptidase II promotes maturation of caspase-1 in Shigella flexneri-induced macrophage apoptosis. Infect Immun 68, 5502-5508.

Hogquist, K. A., Nett, M. A., Unanue, E. R. \& Chaplin, D. D. (1991). Interleukin-1 is processed and released during apoptosis. Proc Natl Acad Sci U S A 88, 8485-8489.

Hume, P. J., McGhie, E. J., Hayward, R. D. \& Koronakis, V. (2003). The purified Shigella IpaB and Salmonella SipB translocators share biochemical properties and membrane topology. Mol Microbiol 49, 425-439.

Islam, D., Veress, B., Bardhan, P. K., Lindberg, A. A. \& Christensson, B. (1997). In situ characterization of inflammatory responses in the rectal mucosae of patients with Shigellosis. Infect Immun 65, 739-749.

Jacobsen, M. D., Weil, M. \& Raff, M. C. (1996). Role of Ced-3/ICEfamily proteases in staurosporine-induced programmed cell death. J Cell Biol 133, 1041-1051.

Koterski, J. F., Nahvi, M., Venkatesan, M. M. \& Haimovich, B. (2005). Virulent Shigella flexneri causes damage to mitochondria and triggers necrosis in infected human monocyte-derived macrophages. Infect Immun 73, 504-513.

Kuwae, A., Yoshida, S., Tamano, K., Mimuro, H., Suzuki, T. \& Sasakawa, C. (2001). Shigella invasion of macrophage requires the insertion of IpaC into the host plasma membrane. Functional analysis of IpaC. J Biol Chem 276, 32230-32239.

Lafont, F., Tran Van Nhieu, G., Hanada, K., Sansonetti, P. \& van der Goot, F. G. (2002). Initial steps of Shigella infection depend on the cholesterol/sphingolipid raft-mediated CD44-IpaB interaction. EMBO J 21, 4449-4457.

Li, P., Allen, H., Banerjee, S., Franklin, S., Herzog, L., Johnston, C., McDowell, J., Paskind, M., Rodman, L. \& other authors (1995). Mice deficient in IL-1 $\beta$-converting enzyme are defective in production of mature IL-1 $\beta$ and resistant to endotoxic shock. Cell 80, $401-411$.

Linsinger, G., Wilhelm, S., Wagner, H. \& Hacker, G. (1999). Uncouplers of oxidative phosphorylation can enhance a Fas death signal. Mol Cell Biol 19, 3299-3311.

Mariathasan, S., Weiss, D. S., Newton, K., McBride, J., O'Rourke, K., Roose-Girma, M., Lee, W. P., Weinrauch, Y., Monack, D. M. \& Dixit, V. M. (2006). Cryopyrin activates the inflammasome in response to toxins and ATP. Nature 440, 228-232.

Matsuyama, S., Llopis, J., Deveraux, Q. L., Tsien, R. Y. \& Reed, J. C. (2000). Changes in intramitochondrial and cytosolic pH: early events that modulate caspase activation during apoptosis. Nat Cell Biol 2, 318-325.

Maurelli, A. T., Baudry, B., d'Hauteville, H., Hale, T. L. \& Sansonetti, P. J. (1985). Cloning of plasmid DNA sequences involved in invasion of HeLa cells by Shigella flexneri. Infect Immun 49, 164-171.

Ménard, R., Sansonetti, P. J. \& Parsot, C. (1993). Nonpolar mutagenesis of the ipa genes defines IpaB, IpaC, and IpaD as effectors of Shigella flexneri entry into epithelial cells. J Bacteriol 175, 5899-5906.

Ménard, R., Sansonetti, P. \& Parsot, C. (1994a). The secretion of the Shigella flexneri Ipa invasins is activated by epithelial cells and controlled by IpaB and IpaD. EMBO J 13, 5293-5302.

Ménard, R., Sansonetti, P. J., Parsot, C. \& Vasselon, T. (1994b). Extracellular association and cytoplasmic partitioning of the IpaB and IpaC invasins of S. flexneri. Cell 79, 515-525.

Page, A. L., Ohayon, H., Sansonetti, P. J. \& Parsot, C. (1999). The secreted IpaB and IpaC invasins and their cytoplasmic chaperone IpgC are required for intercellular dissemination of Shigella flexneri. Cell Microbiol 1, 183-193.

Parsot, C., Ménard, R., Gounon, P. \& Sansonetti, P. J. (1995). Enhanced secretion through the Shigella flexneri Mxi-Spa translocon leads to assembly of extracellular proteins into macromolecular structures. Mol Microbiol 16, 291-300.

Perregaux, D. \& Gabel, C. A. (1994). Interleukin-1 $\beta$ maturation and release in response to ATP and nigericin. Evidence that potassium depletion mediated by these agents is a necessary and common feature of their activity. J Biol Chem 269, 15195-15203.

Rathman, M., Jouirhi, N., Allaoui, A., Sansonetti, P., Parsot, C. \& Tran Van Nhieu, G. (2000). The development of a FACS-based strategy for the isolation of Shigella flexneri mutants that are deficient in intercellular spread. Mol Microbiol 35, 974-990.

Rosenberger, C. M. \& Finlay, B. B. (2003). Phagocyte sabotage: disruption of macrophage signalling by bacterial pathogens. Nat Rev Mol Cell Biol 4, 385-396.

Sansonetti, P. J., Kopecko, D. J. \& Formal, S. B. (1982). Involvement of a plasmid in the invasive ability of Shigella flexneri. Infect Immun 35, 852-860.

Sansonetti, P. J., Phalipon, A., Arondel, J., Thirumalai, K., Banerjee, S., Akira, S., Takeda, K. \& Zychlinsky, A. (2000). Caspase-1 activation of IL-1 $\beta$ and IL-18 are essential for Shigella flexneri-induced inflammation. Immunity 12, 581-590. 
Schlumberger, M. C. \& Hardt, W. D. (2006). Salmonella type III secretion effectors: pulling the host cell's strings. Curr Opin Microbiol 9, 46-54.

Schlumberger, M. C., Muller, A. J., Ehrbar, K., Winnen, B., Duss, I., Stecher, B. \& Hardt, W. D. (2005). Real-time imaging of type III secretion: Salmonella SipA injection into host cells. Proc Natl Acad Sci U S A 102, 12548-12553.

Schroeder, G. N. \& Hilbi, H. (2006). Cholesterol is required to trigger caspase-1 activation and macrophage apoptosis after phagosomal escape of Shigella. Cell Microbiol 9, 265-278.

Schuch, R., Sandlin, R. C. \& Maurelli, A. T. (1999). A system for identifying post-invasion functions of invasion genes: requirements for the Mxi-Spa type III secretion pathway of Shigella flexneri in intercellular dissemination. Mol Microbiol 34, 675-689.

Skoudy, A., Mounier, J., Aruffo, A., Ohayon, H., Gounon, P., Sansonetti, P. \& Tran Van Nhieu, G. (2000). CD44 binds to the Shigella IpaB protein and participates in bacterial invasion of epithelial cells. Cell Microbiol 2, 19-33.

Stecher, B., Hapfelmeier, S., Muller, C., Kremer, M., Stallmach, T. \& Hardt, W. D. (2004). Flagella and chemotaxis are required for efficient induction of Salmonella enterica serovar Typhimurium colitis in streptomycin-pretreated mice. Infect Immun 72, 4138-4150.

Suzuki, T., Nakanishi, K., Tsutsui, H., Iwai, H., Akira, S., Inohara, N., Chamaillard, M., Nunez, G. \& Sasakawa, C. (2005). A novel caspase$1 /$ toll-like receptor 4-independent pathway of cell death induced by cytosolic Shigella in infected macrophages. J Biol Chem 280, 14042-14050.

Tamano, K., Aizawa, S., Katayama, E., Nonaka, T., Imajoh-Ohmi, S., Kuwae, A., Nagai, S. \& Sasakawa, C. (2000). Supramolecular structure of the Shigella type III secretion machinery: the needle part is changeable in length and essential for delivery of effectors. $E M B O J$ 19, 3876-3887.

Thirumalai, K., Kim, K. \& Zychlinsky, A. (1997). IpaB, a Shigella flexneri invasin, colocalizes with interleukin-1 $\beta$ converting enzyme (ICE) in the cytoplasm of macrophages. Infect Immun 65, 787-793.

Tran Van Nhieu, G., Caron, E., Hall, A. \& Sansonetti, P. J. (1999). IpaC induces actin polymerization and filopodia formation during Shigella entry into epithelial cells. EMBO J 18, 3249-3262.

van der Goot, F. G., Tran van Nhieu, G., Allaoui, A., Sansonetti, P. \& Lafont, F. (2004). Rafts can trigger contact-mediated secretion of bacterial effectors via a lipid-based mechanism. J Biol Chem 279, 47792-47798.

Walev, I., Reske, K., Palmer, M., Valeva, A. \& Bhakdi, S. (1995). Potassium-inhibited processing of IL- $1 \beta$ in human monocytes. EMBO J 14, 1607-1614.

Watarai, M., Tobe, T., Yoshikawa, M. \& Sasakawa, C. (1995). Contact of Shigella with host cells triggers release of Ipa invasins and is an essential function of invasiveness. EMBO J 14, 2461-2470.

Wilharm, G., Lehmann, V., Krauss, K., Lehnert, B., Richter, S., Ruckdeschel, K., Heesemann, J. \& Trulzsch, K. (2004). Yersinia enterocolitica type III secretion depends on the proton motive force but not on the flagellar motor components MotA and MotB. Infect Immun 72, 4004-4009.

Zychlinsky, A., Prévost, M. C. \& Sansonetti, P. J. (1992). Shigella flexneri induces apoptosis in infected macrophages. Nature 358, 167-168.

Zychlinsky, A., Fitting, C., Cavaillon, J. M. \& Sansonetti, P. J. (1994a). Interleukin- 1 is released by murine macrophages during apoptosis induced by Shigella flexneri. J Clin Invest 94, 1328-1332.

Zychlinsky, A., Kenny, B., Ménard, R., Prévost, M. C., Holland, I. B. \& Sansonetti, P. J. (1994b). IpaB mediates macrophage apoptosis induced by Shigella flexneri. Mol Microbiol 11, 619-627.

Zychlinsky, A., Thirumalai, K., Arondel, J., Cantey, J. R., Aliprantis, A. \& Sansonetti, P. J. (1996). In vivo apoptosis in Shigella flexneri infections. Infect Immun 64, 5357-5365.

Edited by: D. L. Gally 